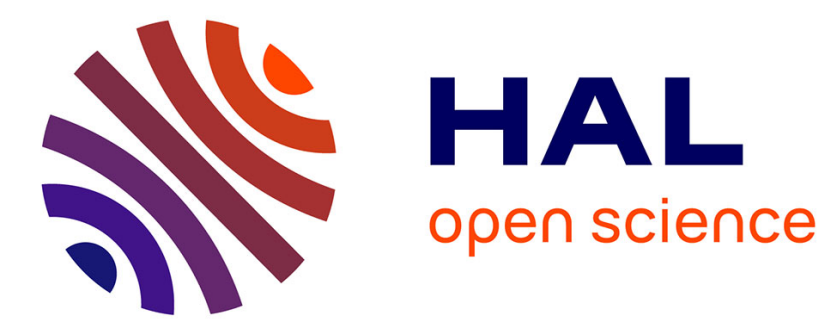

\title{
Off-flavours in wines through indirect transfer of Volatile Organic Compounds (VOCs) from coatings
}

\author{
Maria Daria Fumi, Milena Lambri, Dante Marco de Faveri
}

\section{To cite this version:}

Maria Daria Fumi, Milena Lambri, Dante Marco de Faveri. Off-flavours in wines through indirect transfer of Volatile Organic Compounds (VOCs) from coatings. Food Additives and Contaminants, 2009, 26 (05), pp.759-766. 10.1080/02652030802695498 . hal-00577359

\section{HAL Id: hal-00577359 \\ https://hal.science/hal-00577359}

Submitted on 17 Mar 2011

HAL is a multi-disciplinary open access archive for the deposit and dissemination of scientific research documents, whether they are published or not. The documents may come from teaching and research institutions in France or abroad, or from public or private research centers.
L'archive ouverte pluridisciplinaire HAL, est destinée au dépôt et à la diffusion de documents scientifiques de niveau recherche, publiés ou non, émanant des établissements d'enseignement et de recherche français ou étrangers, des laboratoires publics ou privés. 


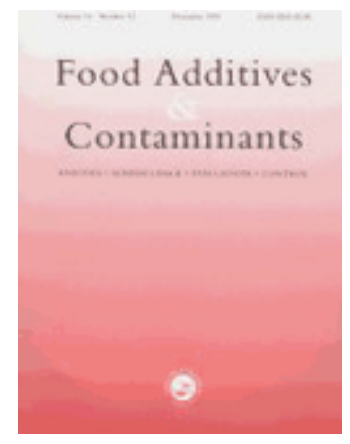

\section{Off-flavours in wines through indirect transfer of Volatile Organic Compounds (VOCs) from coatings}

\begin{tabular}{|c|c|}
\hline Journal: & Food Additives and Contaminants \\
\hline Manuscript ID: & TFAC-2008-235.R1 \\
\hline Manuscript Type: & Original Research Paper \\
\hline $\begin{array}{r}\text { Date Submitted by the } \\
\text { Author: }\end{array}$ & 13-Dec-2008 \\
\hline Complete List of Authors: & $\begin{array}{l}\text { Fumi, Maria Daria; Università Cattolica del Sacro Cuore, Istituto di } \\
\text { Enologia e Ingegneria Alimentare } \\
\text { Lambri, Milena; Università Cattolica del Sacro Cuore, Istituto di } \\
\text { Enologia e Ingegneria Alimentare } \\
\text { De Faveri, Dante; Università Cattolica del Sacro Cuore, Istituto di } \\
\text { Enologia e Ingegneria Alimentare }\end{array}$ \\
\hline Methods/Techniques: & Exposure, Risk assessment, Sensory analysis \\
\hline Additives/Contaminants: & Environmental contaminants, Volatiles \\
\hline Food Types: & Wine \\
\hline \multicolumn{2}{|c|}{$\begin{array}{l}\text { Note: The following files were submitted by the author for peer review, but cannot be converted } \\
\text { to PDF. You must view these files (e.g. movies) online. }\end{array}$} \\
\hline Fumi_Table V.doc & \\
\hline
\end{tabular}

\section{SCHOLARONE \\ Manuscripts}




\section{Off-flavours in wines through indirect transfer of volatile organic compounds (VOCs) from coatings}

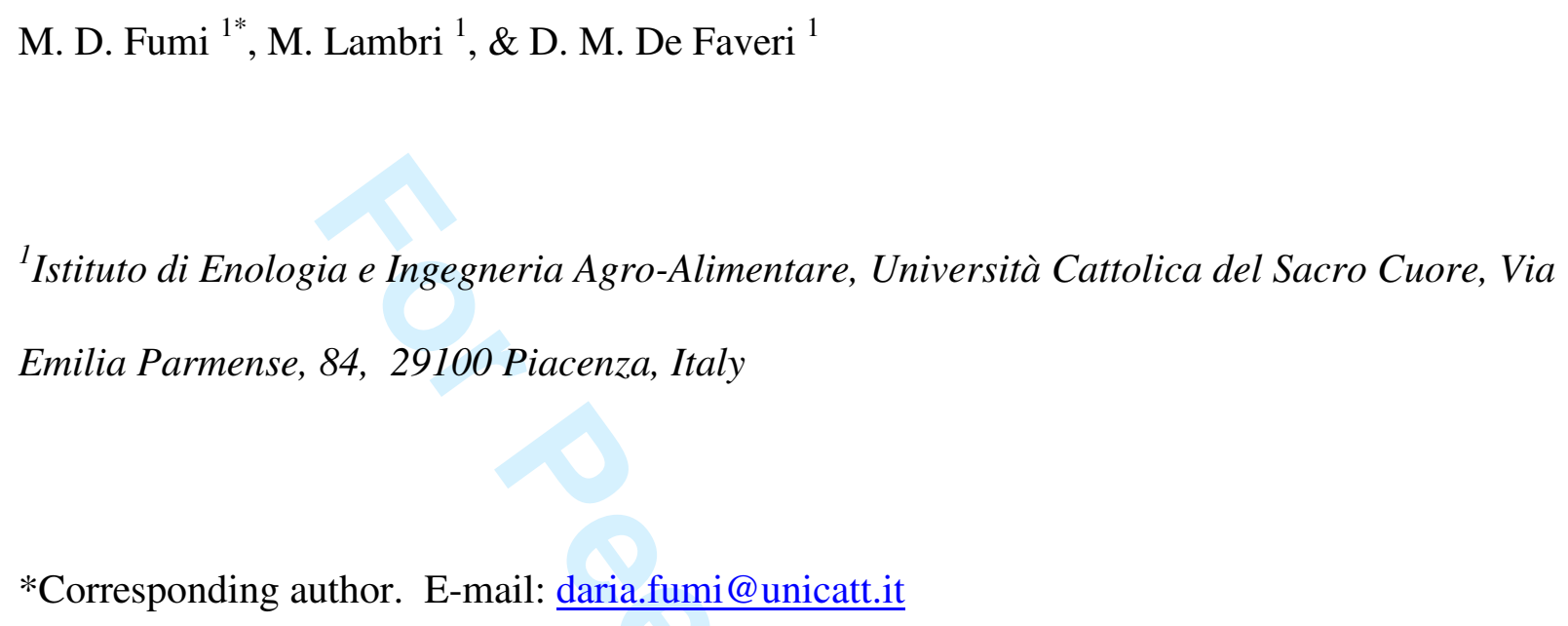

*Corresponding author. E-mail: daria.fumi@unicatt.it 


\begin{abstract}
This paper assesses the impact of VOCs from the drying of coatings on the sensory characters of corks and wines. According to UNI 11021:2002 a small-scale chamber was used 1) to expose wines to the drying of coatings with both low and high VOCs and 2) to expose corks to the same coatings. After exposure to the coatings the corks were then placed in direct contact with wine. Different styles of white, red and rosé wines were tested. In both directly exposed wines and in wines after contact with the exposed cork, the taste and smell off-flavour perception and intensity were assessed by a panel of 8 experienced wine tasters using a 5 point numerical scale according to ISO standard methods. The results showed that the sensory characters of wines, especially taste, were influenced by the VOC content of the coatings. The taste off-flavour perception was found to be higher than the smell in wines exposed to coatings with either high or low VOCs contents. ANOVA and Duncan analysis prove that: a) Panellist's answers were significantly different, b) It was difficult to differentiate the off-flavour perception on the high level scale c) The panellist offflavour perceptions versus wine style discriminated the wines into two groups (red and white/rosè). For all the wine styles, the Pearson's test showed no-significant correlation between off-flavour perception levels and the main chemical characters of the wines. For the wines which were in direct contact with the exposed corks, the panellists detect the off-flavours according to the levels of VOCs in the coating and wine styles and they assessed the highest levels of alteration were to the taste.
\end{abstract}

Keywords: indoor VOCs; coatings; wines; cork stoppers; off-flavours. 


\title{
Introduction
}

Over the past decade it has become evident that volatile organic compounds (VOCs) are the major contributors to the pollution of the indoor environment. VOCs can originate from a variety of sources including building and coating materials such as paints and varnishes (Brown et al. 1994; Clausen 1993; Rothweiler et al. 1993; Seltze 1997; Wolkoff 1995; Yu and Crump, 1998) and they can have an adverse effect on human health as well as a sensory impact on the occupants of buildings (Berglund et al. 1992; Harrison 1997; Holcomb and Seabrook 1995; Jones 1999 ; Knudsen et al.1999; Mølhave 1991; Otto et al. 1992; Stranger et al. 2007; Woolkoff and Nielsen 2001; Woolkoff et al. 2005).

The sensory impact bound to the presence of VOCs is also more important in places where food are manufactured, stored, packed and consumed; because organoleptic alterations can occur, and the consumers' reaction is to reject foods and beverages (Fumi et al. 2004). Moreover evaluating the risks originating from coating materials is a fundamental requirement since the E.U. Directives 43/1993 and 852/2004 on ensuring safety of foodstuffs through the application of the Hazard Analysis Critical Control Points (HACCP) came into force.

\begin{abstract}
A National Standard Method (UNI 11021:2002) has been in place in Italy since 2002 where requirements and test methods are specified for coatings used in environments where foods are likely to be present. In addition to the physical-chemical properties of coatings this standard takes two specific areas into consideration: a) resistance to fungi growth and b) off-flavour release. Offflavour release is one of the essential tests for paints and varnishes intended for use as coatings in indoor environment were foods are handled.
\end{abstract}

The VOCs emissions from coatings are continuous and last for many years in a building (Yu and Crum 1998) so it can have a long-term sensory impact on food present in the environment. 
Consequently it is recommended to use coating products which have a low impact on the air quality from the moment they are applied (Knudsen et al. 1999). The determination of off-flavours due to VOCs emission during the initial period of paints or varnishes application is useful to predict the impact of a coating materials during their entire life on the occupant's wellbeing and on the quality of the foods .

Sensory characteristics are important in food as well as in beverages and above all in wine. In fact wine sensory properties are the result of the interaction of several factors or conditions: geographic origin, biodiversities, cultural traditions, local know-how, technological processes (Clarke and Bakker 2004). Wine tasting has become a pleasant and fashionable activity. Professionally tasting is used to identify wine variety, age, complexity, whether typical and to evaluate the overall wine quality, in the context of consumers' experience the sensory perceptions have to fulfil hedonic expectation. The organoleptic quality of any bottled wine is directly related to its flavour components but indirectly related to compounds released by the cork stoppers. The physical properties of corks such as waterproof, hydrophobicity, and elasticity have encouraged their use for sealing wine bottles especially high-quality wines. Nevertheless, some negative aspects can appear. In fact corks absorb many volatile compounds from the environment (Barker et al. 2001; Pollnitz et al. 1996; Skurray et al. 2000; Strauss et al.1985). So when faulty corks are used for sealing wine bottles, unpleasant substances can migrate into the wine and and off-flavours can occur (Chatonnet et al. 2004; Sefton and Simpson, 2005). It is therefore important to ensure that the properties of wine are not altered by environmental contamination such as VOCs from coatings.

This paper assesses the influence of the drying of coatings with different VOCs levels on wine and cork stopper sensory characters.

\section{Materials and methods}




\section{Paints \\ In-can low VOCs (LV) and high VOCs (HV) water-based paints containing respectively $\leq 30 \mathrm{~g} \mathrm{l}^{-1}$ and $\leq 100 \mathrm{~g} \mathrm{l}^{-1}$ of VOCs according to EU Directive 2004/42 were chosen.}

\section{Experimental design}

The coating impact test on wine flavour was carried out according to UNI 11021:2002.

The tests were performed in a Glass gas-tight chamber with a loading ratio $=\mathrm{S} \mathrm{V}^{-1}$ (Coated surface/Chamber volume) $=3 \mathrm{~m}^{-1}$, simulating a common room. The paint was applied on a glass plate carrier (non adsorbent surface) $100 \mathrm{~mm}$ x $60 \mathrm{~mm}$ x $2 \mathrm{~mm}$.

Immediately after the application of the paint we put the wet specimen (without conditioning) in the chamber where $50 \mathrm{ml}$ of wine in a $100 \mathrm{ml}$ beaker was kept. After 48 hours of exposure at $25^{\circ} \mathrm{C}$ the sensory characters of the wine were estimated.

The corks were exposed, at first in the gas-tight chamber to the same coatings during 48 hours at $25^{\circ} \mathrm{C}$, then placed in direct contact with $50 \mathrm{ml}$ wine for 48 hours at $25^{\circ} \mathrm{C}$. The surface cork area to wine volume ratio was $0.75 \mathrm{~cm}^{-1}$. 
A blind sample was carried out exposing the wine in the gas-tight chamber in the presence of nocoating carrier in order to exclude eventual modifications due to the exposure equipment. From each lot of wines we took 3 times $50 \mathrm{~mL}$ of each and put them into 3 different gas-tight chambers under the same experimental conditions (wet coating, exposure time, temperature). The same procedure was carried out on the blind sample, too.

The sensory alterations were detected: a) in exposing wines directly to fumes from coating and b) in wines after direct contact with the cork previously exposed to fumes from coatings.

\section{Sensory evaluation}

The panellists were experts in wine tasting and were selected and tested according to the ISO 8586 (Part I: 1993; Part II :2008), and ISO 6658 (2005). Eight 30-50 year old panellists (5 females, 3 males) sensory assessors were chosen according to their ability to perceive eventual wine offflavours. The threshold of VOCs off-flavours was determined by ISO 13301 (2002) using solutions of 2-buthoxyethoxyethanol (the main VOCs component of the analysed water-based paints) in tasteless and odourless water. To determine the candidates' ability to discriminate graded levels of intensity of a given attribute a ranking/rating test for intensity by a 5 point numerical category scale anchored with words was used (Meilgaard et al. 2007a, b).

The sensory analysis of wines directly exposed to VOCs fumes and wines kept in contact with corks previously exposed to VOCs fumes were performed by a triangle test according to ISO 41201 (2004). The result was considered significant for $\alpha \leq 0.05$ and $\beta \leq 0.01$, the statistical power of the test was $\mathrm{p} \geq 95 \%$. The sensory analysis laboratory met all the basic criteria regarding equipment and application of the suitable environmental condition according to ISO 8589 (2007). 
Panel screening and training

The 8 selected panellists were screened for their ability to perceive the paint off-flavours stimulus in water exposed in the gas-tight chamber to 2- buthoxyethoxyethanol spaced concentrations $(3 ; 9 ; 27$ $\mu \mathrm{g} \mathrm{m}^{-3}$ ) close to the threshold reported in literature (Knudsen 1999). With this aim in mind a 3AFC test (ISO 13301:2002) was followed.

In order to discriminate graded levels of intensity of VOCs off-flavour, the panellists were asked to rate on a 5 point numerical category scale anchored with words (Meilgaard et al. 2007b) the water samples exposed to ascending 2 - buthoxyethoxyethanol concentration: $2 ; 4.5 ; 9 ; 18 ; 27 \mu \mathrm{g} \mathrm{m}^{-3}$. The panel members were informed on how to use the scale to evaluate the intensity where 0 is = notperceptible; $1=$ perceptible; $2=$ clearly perceptible; $3=$ strongly perceptible; $4=$ very strongly perceptible.

The volume for sample was $50 \mathrm{ml}$, served in clear wine glasses at $20 \pm 1^{\circ} \mathrm{C}$. A control sample of non-exposed water was provided for both detection and ranking/rating tests. The panellist with the highest sensitivity to VOCs off-flavour performed the wine testing.

\section{Wine testing}

According to ISO 41201 (2004) and UNI 11021(2002) the triangle test were carried out on wines exposed and non-exposed to coatings and on wines kept in contact with corks previously exposed to VOCs fumes. In each phase of the test, one or two of the samples for each wine were exposed to applied coating and the position of the exposed sample was randomised. The volume of sample was $50 \mathrm{ml}$, served in clear wine glasses at $20 \pm 1^{\circ} \mathrm{C}$. The panellists were asked to identify the samples that were different by sniffing and by tasting. After the identification of the different samples the panellists were asked to mark the intensity of the off-flavour perception on the above mentioned scale. 
The wines were tested the same day, the panellists analysed 3 replicates of each wine at $30 \mathrm{~min}$ intervals. The number of samples that have been evaluated in one sensory session was decided on the basis of the result of preliminary tests at the end of training of assessors. The first wines to be tested were the wines exposed to low VOCs first white wines having low ethanol contents and proceeding until red wines having high ethanol contents. Then the panellists tasted the wines exposed to high VOCs following the same protocol.

\section{Data analysis}

All the data have been subjected to Microsoft Excel 2003 and to one-way analysis of variance (ANOVA). Correlations between panel sensory perceptions and wine chemical parameters were performed by Pearsons' test. Statistical elaboration was carried out by SPSS software version 13.0 (SPSS Inc., Chicago, Illinois).

\section{Results and discussion}

Impact on the wines of the different VOC levels of the coatings

As we can see in Figure 1 and Figure 2 the taste coating impact is higher than smell coating impact in wines having been exposed to either high or low VOCs content.

As far as the wines exposed to low VOCs (LV) are concerned (Figure 1), the panellists indicate the smell alteration, from not-perceptible (intensity 0 ) to slightly perceptible (intensity 1 ) except for Chardonnay where $10 \%$ of them identified the alteration as clearly perceptible (intensity 2 ).

After tasting (Figure 2), the off-flavour is identified from perceptible (intensity 1) to strongly perceptible (intensity 3). Most panellists assessed the highest taste alteration in Rosé wine. As for the sensory analysis of wines exposed to high VOCs (HV) (Figure 2), the panellists' answers indicated the smell alterations up to clearly perceptible (intensity 2) except for Cabernet 


\section{Impact on panellist off-flavour perceptions of the different VOC levels of the coatings}

The ANOVA analysis of the panellists' answers shows that the differences between the smell and taste perception levels for both coatings were highly significant as far as smell was concerned (Table II). Considering high VOC impact on smell, the Duncan's test (Table III) showed that the panellists' answers were significantly different, in fact their answers can be divided into 4 groups (a,b,c,d reported as superscript letters), but we noted no significant differences between strongly perceptible alteration (intensity 3 ) and very strongly perceptible alteration (intensity 4) nor between clearly perceptible (intensity 2 ) and strongly perceptible alteration (intensity 3 ). However clearly perceptible alteration was distinguishable from very strongly perceptible alteration (intensity 4) and from the others ( 0 and 1 intensity), and in fact we can see that the superscript letters are different. Perceptible alteration (intensity 1 ) is distinguishable from not-perceptible alteration (intensity 0 ) and both from the others. Therefore it means that it is difficult for the panellists to distinguish a strongly perceptible alteration from a very strongly perceptible one and a strongly perceptible alteration from a clearly perceptible one.

In coating with low VOCs (Table III) smell alteration at 0 level has been significantly distinguished by the panellists from intensity 1 and both from 2, 3, 4 intensity level, and in fact we can see that the superscript letters are different. Alterations at 2, 3, 4 intensity level were not easily distinguishable from each other, in fact we get common super-script letter. That means that it was difficult for the panellists to identify the alteration above 1 intensity level. 
As for taste in wine exposed to low VOCs we can note that the panellists clearly distinguished the lowest and the highest alteration levels only (Table III). Even in this situation it was difficult for the panellists to distinguish strongly perceptible and very strongly perceptible as well as clearly perceptible from strongly perceptible, perceptible and not-perceptible. As far as the taste of high VOCs coating was concerned there are no difference between the intensity levels, the off-flavour was detected as very strongly perceptible whatever the type the wine (data not shown).

\section{Panellist off-flavour perceptions versus wine style}

When comparing panel answers versus the wines, ANOVA analysis divides the wines into two groups. In the first group (Table IV) which includes white (Chardonnay and Malvasia) and rosé wines, the panellists clearly perceived different levels of smell alteration, while they identified in Chardonnay also different levels of taste alterations due to the exposure to low VOCs. The second group (Table V) was composed of the two red wines (Cabernet sauvignon and Montepulciano bottle-aged wine), and the panellists perceived a significant olfactory alteration in Cabernet only when VOCs were at a low concentration.

In aged-wine they perceived a significant smell alteration in presence of both low and high VOCs and taste off-flavour according to low VOCs.

\section{Impact on cork of the different VOC levels of the coatings}

In relation to coating impact on cork sensory characters the panellists detected off-flavours in the wine in contact with cork stoppers previously exposed to coating specimens according to VOC levels and wine styles. In fact, after sniffing, we can note in wines exposed to low VOCs (Figure 3), that: in Malvasia all the panellists indicated the alteration as clearly perceptible (intensity 2); in Chardonnay most of them $(70 \%)$ did not assess any alteration $(0=$ not-perceptible $)$ and the other 
$30 \%$ from perceptible (intensity 1 ) to clearly perceptible (intensity 2); in Cabernet the answers were $50 \%$ not-perceptible and $50 \%$ perceptible.

Even in this test, the panellists assessed the highest alteration level to taste in comparison to smell and when comparing high VOCs (Figure 4) and low VOCS coatings (Figure 3) they confirmed that higher VOCs coating have the most important impact on wine flavour.

Our results point out that the panellists are more sensitive to taste than smell alteration. We can suppose that mouth temperature enhanced the volatility of some VOCs and that chemical feeling factors stimulate the taste panellist perceptions. The difficulty for the panellists to distinguish significantly high levels of off-flavour intensity was probably because the mouth off-flavour persistence makes it difficult to compare high alteration levels. Furthermore, the VOCs can interact with the sensory characters of wines having a strong "masking" effect.

Moreover the wine style affected the panel's ability to perceive off-flavour: for example among the white wines the panellists clearly perceived smell alteration in Malvasia, while in Chardonnay they even perceived taste modifications. This suggests that varietal flavour present in Malvasia interacts with the panelists'ability to feel the different levels of taste alteration.

Compared to white and rosé wines, Cabernet Sauvignon and aged -wine were characterized by a strong complex olfactory and gustatory structure which makes the identification of the different alteration levels even more difficult. The Pearson's test (data not reported) showed no-significant correlation between the level of off-flavour perception and the main chemical characters of wines (ethanol, sugar total acidity and phenolic compounds). So this leads us to think that off-flavour perception due to VOCs contamination is mostly influenced by the totality of the volatile part of the 
flavour. As regard paints it is not possible to set a correlation between the quantity of VOCs present in paints and the alteration level in wines.

The low VOC content does not seem to be enough to guarantee good indoor air quality due to the fact that coatings are complex mixtures of chemical substances some of which are present at so low a percentage that it is not possible to quantify them by analysis, but their low threshold strongly influences the quality of indoor air. Moreover, some of them are not considered VOC according to 200/4 E.U. Directive, but they also strongly influence the indoor air quality.

In Europe, a voluntary labelling scheme for building material according to their impact on the indoor air quality has been developed and introduced in Denmark and Scandinavian countries (Yu 1998). The Danish labelling scheme includes the use of pre-determined odour and irritation thresholds to ensure building occupant comfort - The Italian Standard Method UNI 11021:2002 gives information on coating impact on foods to assure food quality and genuine sensory perceptions and fulfil consumers' hedonic expectations.

In conclusion, the evaluation of the impact of coatings having different VOC levels on wine and on cork stopper sensory characters showed that:

- coatings modify sensory characters of wine (mainly taste);

- off-flavour perceptions are correlated to VOC level and wine style;

- cork stoppers are confirmed to be good absorbents of indoor paint contaminants.

These results lead us to conclude that the UNI 11021:2002 method is a great help to easily predict the coating impact on indoor air quality during the different coating manufacturing steps. Moreover these outcomes are helpful to advise manufacturers on how to develop low-polluting coating with low impact on air sensory characters in order to ensure food and beverage quality. 


\begin{abstract}
We are still working on the correlation of indoor VOCs decay kinetics with off-flavour perception intensity in wine and cork stoppers to estimate the shortest time necessary before manufacturing or consuming foods, after coating. Correlation between the off-flavour thresholds in foods and beverages and VOCs content in paints is also still being worked on.
\end{abstract}

\title{
References
}

Barker D.A., Capone D.L., Polnitz A.P., McLean H.J., Francis I.L., Oakey H., Sefton M.A. 2001. Absorption of 2,4,6-trichloroanisole by wine cork via the vapour phase in the enclosed environment. Aust J Grape Wine R. 7:40-46.

Berglund B., Brunekreef B., Knoppler H., Lindvall T., Maroni M., Mølhave L., Skov P. 1992 Effect of indoor air pollution on human health. Ind Air. 2:2-25.

Brown S. K., Sim M. R., Abramson N. J., Gray C. N. 1994. Concentration of organic compounds in indoor air- a review. Ind Air. 4:123-134.

Chatonnet P., Bonnet S., Boutout S., Labadie M.D. 2004. Identification and respondability of 2,4,6,tribromoanisole in musty, corked odors in wine. J Agric Food Chem. 52:1255-1262.

Clarke R. J., Bakker J. 2004. Factors influencing sensory perceptions. In Wine flavour chemistry (pp. 202-204) Oxford, U.K: Blackwell publishing.

Clausen P. 1993. Emission of volatile and semi-volatile organic compounds from water-borne paints, the effect of the film thickness. Ind Air. 3:269-75. 
EU Directive 2004/42. Limitation of emissions of VOCs due to the use of organic solvents in paints and varnishes and vehicle refinishing products.

E.U. Regulation n ${ }^{\circ}$ 2676/90 (1990). Metodi di analisi Comunitari da utilizzare nel settore del Vino. G.U.C.E. L272, 33.

Fumi M.D., Galli R., Pagella C., De Faveri D.M. 2004. Problematiche alimentari da inquinamento indoor. Tecnica Molitoria. 55:215-222.

Harrison P.T.C. 1997. Health impacts of indoor air pollution. Chem Ind. 17:677-681

ISO 4120:2004. Sensory analysis-Methodology- triangle test.

ISO 6658:2005. Sensory analysis-Methodology- General guidance.

ISO 8586-1:1993. Sensory analysis- General guidance for the selection, training and monitoring of assessors. - Part I: Selected assessors.

ISO 8586-2:2008. Sensory analysis - General guidance for the selection, training and monitoring of assessors -- Part 2: Expert sensory assessors

ISO 8589:2007 Sensory analysis-General guidance for design of test rooms.

ISO 13301:2002. Sensory analysis - Methodology - General guidance for measuring odour, flavour and taste detection thresholds by a three-alternative forced-choice (3-AFC) procedure. 
Jones A.P. 1999. Indoor air quality and health. Atmos Environ. 33:4535-4564.

\author{
Knudsen H. N., Kjaer U. D., Nielsen P. A, Wolkoff P. 1999. Sensory and chemical \\ characterization of VOC emissions from building products: impact of concentration and air \\ velocity. Atmos Environ. 33:1217-1230.
}
Meilgaard M., Civille G.V., Carr B.T. 2007a. Selection and training of panel members. In Sensory Evaluation Techniques (pp. 141-172). London, UK: CRC Taylor e Francis Group.

Meilgaard M., Civille G.V., Carr B.T. 2007b. Measuring Responses In Sensory Evaluation Techniques (pp. 45-61). London, UK: CRC Taylor e Francis Group.

Mølhave L. 1991. Indoor climate, air pollution, and human comfort. J Expo Anal Env Epid. 1:6381

Oppl R. 2007. Harmonisation of emission criteria in Europe. Update on some ongoing work . In Emission and Odours from material Proceeding, Brussels, Belgium 17-18 October.

Otto D., Hundel H., House D., Counts W. 1992. Exposure of humans to a volatile organic mixture I. Behavioural assessment. Arch Environ Health. 47:23-30.

Pollnitz A.P., Pardon K.H, Liacopoulos D., Skouroumounis G.K., Sefton M.A. 1996. The analysis of 2,4,6- trichloroanisole and otrher chloroanisoles in tainted wines and corks. Aust J Grape Wine R. 2:184-190. 


\begin{abstract}
Rothweiler H., Mengon W., Meier G., Forss A., Schlatter C. 1993. Emission of Degradation Products of Building Materials in the Indoor Environment-Case studies. Ind Air. 93:465-70.
\end{abstract}

Skurray G., Castets E., Holland B. 2000. Factor affecting cork permeability. Aust Grapegrower and Winemaker. 435:56-60

Sefton M.A. and Simpson R.F. 2005. Compound causing cork taint and the factor affecting their transfer from natural cork closures to wine- a review. Aust J Grape Wine R. 11:226-240.

Seltzer J.M. 1997. Sources, concentrations, and assessment of indoor pollution. In: Indoor Air Pollution and Health pp (11-60) Bardana, E.J., Montanaro, A.(Eds), New York: Marcel Dekker.

Strauss C.R., Wilson B., Williams P.J. 1985. Taints and off-flavour resulting from contamination of wines: a review of some investigations. Aust Grapegrower and Winemaker. 256:20-24.

Stranger M., Potgieter-Vermaak S.S., Van Grieken R. 2007 Comparative overview of indoor air quality in Antwerp, Belgium. Environ Int. 33:789-797

UNI 11021:2002 "Pitture e vernici - Prodotti e sistemi per la verniciatura di ambienti con presenza di alimenti. Requisiti e metodi di prova".

Wolkoff P. 1995. Volatile Organic Compounds-Sources, measurements, emissions and the impact on indoor air quality. Ind Air Supp. 3:9-73.

Woolkoff P., Nielsen G.D. 2001. Organic compounds in indoor air-their relevance for perceived indoor air quality ? Atmos Environ. 35:4407-4417 
Woolkoff P., Clausen P. A., Wilkins C.K., Nielsen G.D. 2005. Organic compounds in office environments-sensory irritation, odour, measurements and the role of reactive chemistry. Ind Air. $16: 7-19$

Yu C., Crump D. 1998. A review of the emission of VOCs from Polymeric Materials used in buildings. B Environ. 33:357-374. 


\section{$1 \quad$ Figure captions}

2

3 Figure 1. Impact of Low VOCs (LV) coating on flavours of wines. Histogram of frequency

4 distribution of the off-flavour score.

5

6 Figure 2. Impact of High VOCs (HV) coating on flavours of wines Histogram of frequency

7 distribution of the off-flavour score.

8

9 Figure 3. Impact of cork stoppers, previously exposed to Low VOCs (LV) coating specimen, on

10 flavours of wines. Histogram of frequency distribution of the off-flavour score.

12 Figure 4. Impact of cork stoppers, previously exposed to High VOCs (HV) coating specimen, on 13 flavours of wines. Histogram of frequency distribution of the off-flavour score. 
Figure 1. Impact of Low VOCs (LV) coating on flavours of wines. Histogram of frequency distribution of the off-flavour score. $130 \times 97 \mathrm{~mm}(120 \times 120$ DPI $)$ 
Figure 2. Impact of High VOCs (HV) coating on flavours of wines Histogram of frequency distribution of the off-flavour score. $136 \times 97 \mathrm{~mm}(120 \times 120$ DPI $)$ 
Figure 3. Impact of cork stoppers, previously exposed to Low VOCs (LV) coating specimen, on flavours of wines. Histogram of frequency distribution of the off-flavour score. $136 \times 97 \mathrm{~mm}(120 \times 120 \mathrm{DPI})$ 


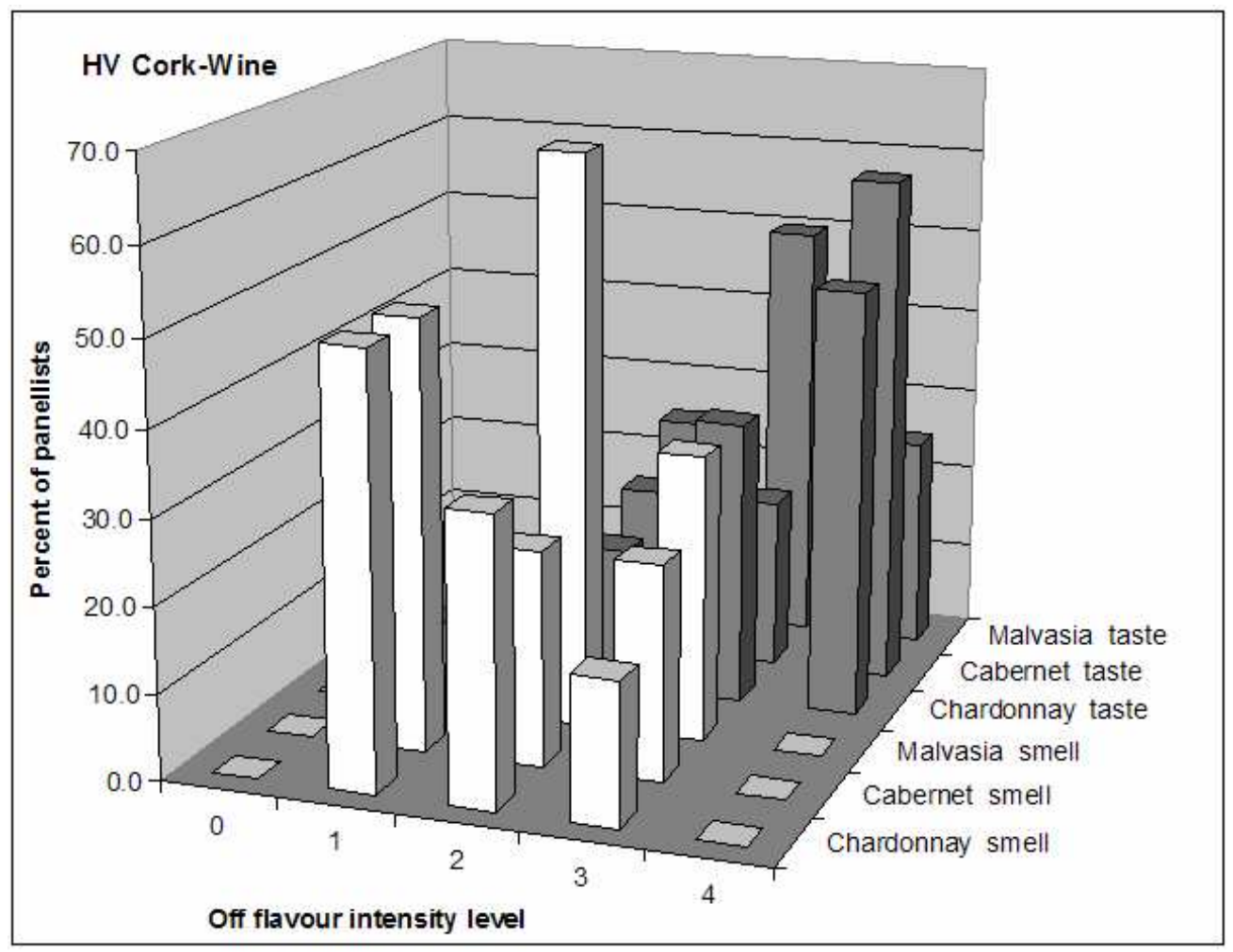

Figure 4. Impact of cork stoppers, previously exposed to High VOCs (HV) coating specimen, on flavours of wines. Histogram of frequency distribution of the off-flavour score. $136 \times 105 \mathrm{~mm}(120 \times 120 \mathrm{DPI})$ 
Table I. Wine denomination and analytical characters of the wines used for the tests.

\begin{tabular}{|c|c|c|c|c|c|}
\hline Wines & $\begin{array}{l}\text { Ethanol } \\
\left(\% \mathbf{v ~ v}^{-1}\right)\end{array}$ & $\begin{array}{c}\text { Sugars } \\
\left(\mathrm{g} \mathrm{l}^{-1}\right)\end{array}$ & pH & $\begin{array}{c}\text { Total acidity } \\
\left(\text { g tartaric acid } \mathbf{l}^{-1}\right)\end{array}$ & $\begin{array}{c}\text { Total Phenols } \\
\text { (Folin-Ciocalteu } \\
\text { index) }\end{array}$ \\
\hline Chardonnay & 11.70 & 7.0 & 3.50 & 5.7 & 7 \\
\hline Malvasia & 7.55 & 65.0 & 3.50 & 6.0 & 6 \\
\hline Rosè & 11.20 & 5.0 & 3.50 & 5.3 & 20 \\
\hline $\begin{array}{l}\text { Cabernet } \\
\text { Sauvignon }\end{array}$ & 13.90 & 3.0 & 3.70 & 5.0 & 67 \\
\hline Bottle-Aged Red & 11.50 & 2.5 & 3.85 & 5.6 & 46 \\
\hline
\end{tabular}


Table II. Impact of VOCs Coating on flavours of wines: significance of panellist's answers.

\begin{tabular}{ccc}
\hline Parameter & F & $\boldsymbol{p}$ \\
\hline HV_Smell & 16.58 & 0.001 \\
HV_Taste & 4.25 & 0.05 \\
LV_Smell & 45.95 & 0.001 \\
LV_Taste & 3.49 & 0.05 \\
\hline
\end{tabular}

The panel was constituted of 8 tasters.

For each parameter 3 replicate sets of each wine were presented to each taster.

For each parameter the Fisher Test (F) and the significance level $(p)$ are reported. 
Table III. Impact of VOCs coating on smell and taste of wines: panellist response frequencies \%.

\begin{tabular}{cccc}
\hline Alteration intensity level & $\begin{array}{c}\text { High VOCs } \\
\text { Smell }\end{array}$ & $\begin{array}{c}\text { Low VOCs } \\
\text { Smell }\end{array}$ & $\begin{array}{c}\text { Low VOCs } \\
\text { Taste }\end{array}$ \\
\hline $\begin{array}{c}4 \\
\text { (very strongly perceptible) } \\
3\end{array}$ & $0.0^{\mathrm{a}}$ & $0.0^{\mathrm{a}}$ & $1.9^{\mathrm{a}}$ \\
$\begin{array}{c}\text { (strongly perceptible) } \\
2\end{array}$ & $2.4^{\mathrm{ab}}$ & $0.0^{\mathrm{a}}$ & $10.7^{\mathrm{ab}}$ \\
$\begin{array}{c}\text { (clearly perceptible) } \\
1 \\
(\text { perceptible) } \\
0\end{array}$ & $16.2^{\mathrm{b}}$ & $7.6^{\mathrm{a}}$ & $22.5^{\mathrm{bc}}$ \\
$\begin{array}{c}\text { (not perceptible) } \\
\end{array}$ & $30.9^{\mathrm{c}}$ & $35.9^{\mathrm{b}}$ & $28.4^{\mathrm{c}}$ \\
\hline
\end{tabular}

The panel was constituted of 8 tasters.

For each parameter 3 replicate sets of each wine were presented to each taster.

For each parameter the Duncan test at $p \leq 0.05$ is reported.

Different super-script letters (a, b, c, d) mean significant differences between data. 
Table IV. Impact of VOCs Coating on flavours of rosè and white wines: significance of panellist's answers versus the wines.

\begin{tabular}{cccccccc}
\hline & \multicolumn{2}{c}{ Rosè } & \multicolumn{2}{c}{ Malvasia } & \multicolumn{2}{c}{ Chardonnay } \\
\hline Parameter & F & $\boldsymbol{p}$ & F & $\boldsymbol{p}$ & $\mathbf{F}$ & $\boldsymbol{p}$ \\
\hline HV_Smell & 20.42 & 0.001 & 5.15 & 0.05 & 7.90 & 0.01 \\
HV_Taste & 0.72 & n.s. & 1.73 & n.s. & 0.75 & n.s. \\
LV_Smell & 23.37 & 0.001 & 49.01 & 0.001 & 8.53 & 0.01 \\
LV_Taste & 1.14 & n.s. & 2.07 & n.s. & 8.78 & 0.01 \\
\hline
\end{tabular}

The panel was constituted of 8 tasters.

For each parameter 3 replicate sets of each wine were presented to each taster.

For each parameter the Fisher Test (F) and the significance level $(p)$ are reported.

n.s. $=$ not significant 
Table V. Impact of VOCs Coating on flavours of red wines: panellist's answers versus the wines.

\begin{tabular}{ccccc}
\hline & \multicolumn{2}{c}{ Aged -Wine } & \multicolumn{2}{c}{ Cabernet sauvignon } \\
\hline Parameter & F & $\boldsymbol{p}$ & F & $\boldsymbol{p}$ \\
\hline HV_Smell & 4.32 & 0.05 & 1.79 & $\mathrm{n} . \mathrm{s}$ \\
HV_Taste & 1.04 & n.s. & 0.73 & $\mathrm{n} . \mathrm{s}$ \\
LV_Smell & 8.72 & 0.01 & 77.56 & 0.001 \\
LV_Taste & 3.53 & 0.05 & 2.67 & n.s. \\
\hline
\end{tabular}

The panel was constituted of 8 tasters.

For each parameter 3 replicate sets of each wine were presented to each taster.

For each parameter the Fisher Test (F) and the significance level ( $p$ ) are reported.

n.s. $=$ not significant 